\title{
Loss Aversion Under Prospect Theory: A Parameter-Free Measurement
}

\author{
Mohammed Abdellaoui \\ CNRS-GREGHEC and HEC School of Management, Paris, F-78350 Jouy-en-Josas, France, \\ abdellaoui@hec.fr \\ Han Bleichrodt \\ Department of Economics, Erasmus University, 3000 DR Rotterdam, The Netherlands, \\ bleichrodt@few.eur.nl \\ Corina Paraschiv \\ Université de Paris V and GREGHEC, Paris, F-78350 Jouy-en-Josas, France, \\ paraschiv@hec.fr
}

\begin{abstract}
A growing body of qualitative evidence shows that loss aversion, a phenomenon formalized in prospect theory, can explain a variety of field and experimental data. Quantifications of loss aversion are, however, hindered by the absence of a general preference-based method to elicit the utility for gains and losses simultaneously. This paper proposes such a method and uses it to measure loss aversion in an experimental study without making any parametric assumptions. Thus, it is the first to obtain a parameter-free elicitation of prospect theory's utility function on the whole domain. Our method also provides an efficient way to elicit utility midpoints, which are important in axiomatizations of utility. Several definitions of loss aversion have been put forward in the literature. According to most definitions we find strong evidence of loss aversion, at both the aggregate and the individual level. The degree of loss aversion varies with the definition used, which underlines the need for a commonly accepted definition of loss aversion.
\end{abstract}

Key words: prospect theory; loss aversion; utility for gains and losses; elicitation of midpoints

History: Accepted by George Wu, decision analysis; received February 16, 2006. This paper was with the authors 3 months and 1 week for 1 revision. Published online in Articles in Advance August 3, 2007.

\section{Introduction}

Economic analyses of decision under risk commonly assume that people maximize expected utility. Much empirical evidence suggests, however, that people systematically violate expected utility theory (Camerer 1995, Starmer 2000). For example, measurements of utility under expected utility have often led to inconsistencies (Hershey and Schoemaker 1985). Rabin (2000) showed that the commonly observed degree of risk aversion over small stakes implies an unrealistic degree of risk aversion over large stakes under expected utility. The danger of using biased utilities is, obviously, that predictions of decisions will be distorted.

One important reason why people deviate from expected utility is loss aversion: People interpret outcomes as gains and losses relative to a reference point and are more sensitive to losses than to absolutely commensurate gains. Many empirical studies have found evidence of loss aversion (e.g., Kahneman et al. 1990, Tversky and Kahneman 1991, Barberis et al. 2001). Loss aversion can also explain a variety of field data (Camerer 2000). Important examples are the equity premium puzzle (Mehra and Prescott 1985, Benartzi and Thaler 1995), asymmetric price elasticities (Hardie et al. 1993), downward-sloping labor supply (Dunn 1996, Camerer et al. 1997, Goette et al. 2004), and the buying strategies of hog farmers (Pennings and Smidts 2003). Rabin (2000) argued that loss aversion can account for the modest-scale risk aversion for both large and small stakes that is typically observed in empirical studies and that expected utility cannot explain. Novemsky and Kahneman (2005) observed that risk aversion in mixed gambles involving small stakes can be attributed exclusively to loss aversion. A formal theory of loss aversion is prospect theory, currently the most popular theory of decision under risk (Kahneman and Tversky 1979, Tversky and Kahneman 1992).

To measure loss aversion, the utility for gains and for losses must be determined simultaneously, i.e., utility must be determined completely. To achieve this, the existing methods for measuring loss aver- 
sion impose additional (e.g., parametric) assumptions. The main problem in designing a method to measure utility completely is that prospect theory assumes that people weight probabilities and that probability weighting for gains may be different from probability weighting for losses. Wakker and Deneffe (1996) showed how utility can be measured for gains and losses separately under prospect theory. Their method, the trade-off method, is robust to probability weighting when all outcomes are of the same sign. The trade-off method does not, however, allow measuring the utility for gains and losses simultaneously; i.e., it does not allow for the measurement of loss aversion.

The purpose of this paper is to measure loss aversion at the individual level and without making parametric assumptions. We, thus, obtain a parameter-free method to completely measure utility under prospect theory. There are several advantages of using nonparametric instead of parametric measurements. First, parametric measurements depend on the appropriateness of the selected functional forms so that one does not know whether the measurements are driven by the data or by the imposed parametric assumptions. A second advantage of nonparametric measurements is that they provide a direct link between utilities and choices. This is important for descriptive reasons because examining the observed choices gives insight into the psychological reasoning that underlies the data. The direct link between utilities and choices is also important for prescriptive decision analysis, because it allows solving inconsistencies in utility measurement. If inconsistencies are observed then these can be immediately related to particular choices and resolving these inconsistencies will yield new insights into what a client's true values are. Under parametric measurements there is no direct link between utilities and choices and, hence, they provide no insight into the processes underlying the data and they are not suitable for prescriptive analyses.

Our method is based on the elicitation of utility midpoints. Utility midpoints have often been used in axiomatizations of decision models. A central step in our method is the elicitation of probabilities (for decision under risk) or events (for decision under uncertainty) that have a decision weight of 0.5 . Such events can be interpreted as a generalization of Ramsey's (1931) ethically neutral events, i.e., events with subjective probability 0.5 under expected utility, to prospect theory.

In the experiment, described in $\$ 4$, we use our method to completely elicit utility under prospect theory. After we determine the utility for gains and losses, we can measure the degree of loss aversion according to the various definitions of loss aversion that have been put forward in the literature. We find clear evidence of loss aversion according to most definitions, both at the aggregate and at the individual level. The different definitions of loss aversion lead, however, to different results, which emphasizes the need for a commonly accepted definition of loss aversion. This issue will be discussed in further detail in $\S 6$.

The elicitation of utility also allows for a test of prospect theory's assumption that utility is concave for gains and convex for losses. Previous studies generally found that utility was concave for gains, but for losses the evidence is less clear-cut: Most studies found (slightly) convex utility for losses, but for a sizeable proportion of subjects the utility for losses was linear or concave. Most of these measurements either assumed expected utility or specific parametric forms of utility, which may have led to biased measurements. In our data we find clear support for prospect theory: Concave utility on the gain domain and convex utility on the loss domain hold both at the aggregate and at the individual level.

In what follows, \$2 reviews prospect theory and the existing empirical evidence on loss aversion and the utility for gains and losses. Section 3 describes our method for the estimation of the utility for gains and losses under prospect theory. Section 4 describes the design of an experiment that elicited the utility function using the method described in \$3. Section 5 presents the results of the experiment. Section 6 discusses the results and concludes.

\section{Background}

\subsection{Prospect Theory}

We consider an individual who has to make a choice under risk between prospects with at most two distinct outcomes. On the domain of two-outcome prospects, original prospect theory (Kahneman and Tversky 1979) and new (or cumulative) prospect theory (Tversky and Kahneman 1992) coincide, and hence our derivations and estimations are valid for both theories.

We write $(x, p ; y)$ for the prospect that results in outcome $x$ with probability $p$ and in outcome $y$ with probability $1-p$. The individual has preferences over prospects and we use the conventional notation $\succ$, $\succeq$, and $\sim$ to represent the relations of strict preference, weak preference, and indifference. Outcomes are monetary and more money is always preferred. If $x=y$, the prospect is riskless, otherwise it is risky. Outcomes are expressed as changes with respect to the status quo or reference point, i.e., as gains or losses. Throughout the paper, we assume that the reference point is 0 . A prospect that involves both a gain and 
a loss outcome is called mixed, otherwise it is nonmixed. For notational convenience, we assume that all prospects $(x, p ; y)$ are rank-ordered. If a nonmixed prospect involves only gains [losses], we assume that $x \geq y \geq 0[x \leq y \leq 0]$, i.e., the first outcome in a nonmixed prospect is always the most extreme. For mixed prospects we assume that $x>0>y$.

The individual evaluates each prospect and chooses the prospect that offers the highest overall utility. The overall utility of a prospect is expressed in terms of three functions: a probability weighting function $w^{+}$ for gains, a probability weighting function $w^{-}$for losses, and a utility function $U$. The functions $w^{+}$ and $w^{-}$assign a probability weight to each probability. They are strictly increasing and satisfy $w^{+}(0)=$ $w^{-}(0)=0$ and $w^{+}(1)=w^{-}(1)=1$. The utility function $U$ assigns a real number to each outcome, which reflects the desirability of that outcome. The function $U$ is increasing and satisfies $U(0)=0 . U$ is a ratio scale, i.e., we can arbitrarily choose the unit of the function.

The evaluation of a prospect depends amongst other things on the sign of the outcomes. If the prospect $(x, p ; y)$ is nonmixed then its utility is

$$
w^{i}(p) U(x)+\left(1-w^{i}(p)\right) U(y),
$$

where $i=+$ for gains and $i=-$ for losses. If the prospect $(x, p ; y)$ is mixed then its utility is

$$
w^{+}(p) U(x)+w^{-}(1-p) U(y) .
$$

Kahneman and Tversky (1979) assumed that the probability weighting functions $w^{+}$and $w^{-}$overweight small probabilities and underweight moderate and high probabilities, giving rise to an inverse S-shaped probability weighting function. The utility function is assumed to be concave for gains and convex for losses, and steeper for losses than for gains.

\subsection{Shape of Utility}

Let us next turn to the empirical evidence on the predictions made by prospect theory. We focus on loss aversion and utility in this paper. Empirical studies on the probability weighting function have generally confirmed that small probabilities are overweighted and moderate and large probabilities are underweighted (Tversky and Kahneman 1992, Camerer and Ho 1994, Tversky and Fox 1995, Wu and Gonzalez 1996, Gonzalez and Wu 1999, Abdellaoui 2000, Bleichrodt and Pinto 2000).

Empirical measurements have corroborated that the utility for gains is concave. This holds both when expected utility is assumed (e.g., Fishburn and Kochenberger 1979) and when prospect theory is assumed (Fennema and van Assen 1998, Abdellaoui 2000, Abdellaoui et al. 2005).
The evidence on the utility for losses is less clearcut. Several studies determined the utility for losses under the assumption that expected utility holds. Most of these studies found convex utility for losses for the majority of cases (Fishburn and Kochenberger 1979, Pennings and Smidts 2003), but a sizeable minority of subjects, around $40 \%$, had concave utility for losses. The assumption of expected utility in these studies led to a bias in the direction of convexity of the utility function. They determined utility by comparing a sure loss with a two-outcome prospect that offered a probability $p$ of a larger loss and a probability $1-p$ of no loss. The probabilities used exceeded $1 / 3$. Under prospect theory, probabilities above $1 / 3$ are generally underweighted making such risky losses more attractive relative to sure losses of equivalent expected value and, hence, enhancing risk seeking.

Under expected utility, convexity of utility is equivalent to risk seeking. Under prospect theory, this equivalence no longer holds. For example, if a subject indicates that he is indifferent between a sure loss of $€ 40$ and the two-outcome prospect $(-€ 100,1 / 2$; $€ 0$ ), then Equation (1) reveals that this risk-seeking preference is consistent with a concave utility for money if $w^{-}(1 / 2)<0.4$. Therefore, previous findings of riskseeking behavior for losses (e.g., Laughhunn et al. 1980, Currim and Sarin 1989, Myagkov and Plott 1997, Heath et al. 1999) provide, under prospect theory, no conclusive evidence in favor of convex utility for losses.

The following studies have estimated the utility for losses under prospect theory, thereby avoiding bias due to probability weighting. Tversky and Kahneman (1992) assumed a power function for the utility for losses and a one-parameter functional form for probability weighting and found a median power coefficient of 0.88 , which corresponds to a slightly convex utility for losses; no individual data are given. Fennema and van Assen (1998), Abdellaoui (2000), Etchart-Vincent (2004), Schunk and Betsch (2006), and Booij and van de Kuilen (2006) used the tradeoff method (Wakker and Deneffe 1996) to elicit the utility function for losses. The findings from these studies are similar. At the aggregate level, they all found slightly convex utility for losses (median power coefficients vary between 0.84 and 0.97 ). At the individual level, the most common pattern was convex utility for losses (between $24 \%$ and $47 \%$ of the subjects), but concave and linear utility functions were also common.

\subsection{Loss Aversion}

Many empirical studies have confirmed the importance of loss aversion. A significant source of evidence comes from the observed disparities between people's maximum willingness to pay (WTP) to obtain 
various goods and their minimum willingness to accept (WTA) in exchange for giving those goods up. Median and mean WTA values have been found to be between 1.4 and 16.5 times as large as the corresponding WTP values (Kahneman et al. 1990). Although these studies provide some insight into the degree of loss aversion, it is hard to estimate the degree of loss aversion because other factors such as substitution and income effects may have affected the comparison.

A complication in the measurement of loss aversion is that there is no agreed-on definition of loss aversion. Kahneman and Tversky (1979) proposed that loss aversion should be defined by $-U(-x)>$ $U(x)$ for all $x>0$. This suggests that a loss aversion coefficient could be defined as the mean or median of $-U(-x) / U(x)$ over the relevant values of $x$. Tversky and Kahneman (1992) implicitly used $-U(-\$ 1) / U(\$ 1)$ as an index of loss aversion. ${ }^{1}$ Neilson (2002) proposed to define loss aversion by $U(-x) /$ $-x \geq U(y) / y$ for all positive $x$ and $y$. It is not obvious how to define a coefficient of loss aversion for this definition. One possible candidate is the ratio of the infinum of $U(-x) /-x$ over the supremum of $U(y) / y$, $x, y>0$. Wakker and Tversky (1993) defined loss aversion as the requirement that $U^{\prime}(-x) \geq U^{\prime}(x)$ for all $x>$ 0 , i.e., the slope of the utility function at each loss is at least as large as the slope of the utility function at the absolutely commensurate gain, and provided a preference axiomatization. Their definition can be related to a loss aversion coefficient of the mean or median of $U^{\prime}(-x) / U^{\prime}(x)$. A stronger definition was used by Bowman et al. (1999): Loss aversion holds if $U^{\prime}(-x) \geq$ $U^{\prime}(y)$ for all positive $x$ and $y$. That is, the slope of the utility function for losses is everywhere steeper than the slope of the utility function for gains. Neilson (2002) gave a preference foundation for this definition. A possible resulting candidate for a coefficient of loss aversion is $\inf U^{\prime}(-x) / \sup U^{\prime}(y), x, y>0$. In a recent paper Köbberling and Wakker (2005) argued to define the loss aversion coefficient as $U_{\uparrow}^{\prime}(0) / U_{\downarrow}^{\prime}(0)$, where $U_{\uparrow}^{\prime}(0)$ stands for the left derivative and $U_{\downarrow}^{\prime}(0)$ for the right derivative of $U$ at the reference point. A similar definition was suggested by Benartzi and Thaler (1995). Schmidt and Zank (2005) proposed another, behavioral, definition of loss aversion, which is equivalent to the definition of Kahneman and Tversky (1979) under original prospect theory. Because original and new prospect theory coincide for the domain of prospects considered in this paper, we do not have to consider their definition separately.

Table 1 gives an overview of studies that have estimated a loss aversion coefficient. Bleichrodt et al. (2001) estimated two loss aversion coefficients using

${ }^{1}$ This follows from their choice of a power utility function.
Table 1 Estimates of the Loss Aversion Coefficient

\begin{tabular}{lccc}
\hline Study & Definition & Domain & Estimates \\
\hline Fishburn and Kochenberger (1979) & $\frac{U^{\prime}(-x)}{U^{\prime}(x)}$ & Money & 4.8 \\
Tversky and Kahneman (1992) & $\frac{-U(-1)}{U(1)}$ & Money & 2.25 \\
Bleichrodt et al. (2001) & $\frac{-U(-x)}{U(x)}$ & Health & 2.17 \\
Schmidt and Traub (2002) & $\frac{U^{\prime}(-x)}{U^{\prime}(x)}$ & Money & 1.43 \\
Pennings and Smidts (2003) & $\frac{U^{\prime}(-x)}{U^{\prime}(x)}$ & Money & 1.81 \\
Booij and van de Kuilen (2006) & $\frac{U_{\uparrow}^{\prime}(0)}{U_{\downarrow}^{\prime}(0)}$ & Money & 1.79 \\
& & & 1.74 \\
\hline
\end{tabular}

different data sets. Booij and van de Kuilen (2006) estimated separate loss aversion coefficients for high and low monetary amounts. The different studies, besides adopting different parametric assumptions about utility and probability weighting, used different definitions of loss aversion. The estimated values for the coefficient of loss aversion vary, but are hard to compare because of the different assumptions and definitions used, and because some studies reported median values (Fishburn and Kochenberger 1979, Tversky and Kahneman 1992, Bleichrodt et al. 2001) and others mean values.

The estimates in Table 1 are based on aggregate data. Two studies examined loss aversion at the individual level. Both studies performed qualitative tests rather than quantitative measurements. Schmidt and Traub (2002) used the definition of Wakker and Tversky (1993) and found that 33\% of their subjects were loss averse. Twenty-four percent of their subjects behaved exactly opposite to loss aversion, i.e., they behaved as if they focused more on gains than on losses, a response pattern that we will label gain seeking. Bleichrodt and Pinto (2002) used the definition of Kahneman and Tversky (1979) in a decision context involving health outcomes and no risk, and found that the proportion of loss averse subjects varied between $5 \%$ and $30 \%$ across experiments. The proportion of gain-seeking subjects was very low, between $0 \%$ and $2.5 \%$.

\section{Elicitation Procedure}

The procedure to estimate the utility for gains and losses consists of four steps and is summarized in Table 2. The second column of the table describes the quantity that is assessed, the third the indifference that is sought, and the fourth the implication of this indifference under prospect theory. The final column shows the variables that have to be specified and 
Table 2 Four-Step Elicitation Procedure

\begin{tabular}{|c|c|c|c|c|}
\hline & Assessed quantity & Indifference & Under prospect theory & Choice variables* \\
\hline \multirow[t]{2}{*}{ Step 1} & $\begin{array}{l}\mathscr{L}_{1} \\
\mathscr{L}_{2} \\
p_{\ell}\end{array}$ & $\left.\begin{array}{c}\left(\mathscr{L}_{1}, p ; \mathscr{L}^{*}\right) \sim\left(\mathscr{L}_{0}, p ; \mathscr{L}\right) \\
\left(\mathscr{L}_{2}, p ; \mathscr{L}^{*}\right) \sim\left(\mathscr{L}_{1}, p ; \mathscr{L}\right) \\
\mathscr{L}_{1} \sim\left(\mathscr{L}_{2}, p_{\ell} ; \mathscr{L}_{0}\right)\end{array}\right\}$ & $\begin{array}{c}U\left(\mathscr{L}_{0}\right)-U\left(\mathscr{L}_{1}\right)=U\left(\mathscr{L}_{1}\right)-U\left(\mathscr{L}_{2}\right) \\
w^{-}\left(p_{\ell}\right)=0.5\end{array}$ & $\begin{array}{c}p=0.33 \\
\mathscr{L}^{*}=-100 \\
\mathscr{L}=-600 \\
\mathscr{L}_{0}=-1,000\end{array}$ \\
\hline & $\begin{array}{l}\mathscr{G}_{1} \\
\mathscr{G}_{2} \\
p_{g}\end{array}$ & $\left.\begin{array}{c}\left(\mathscr{G}_{1}, p ; \mathscr{G}^{*}\right) \sim\left(\mathscr{G}_{0}, p ; \mathscr{G}\right) \\
\left(\mathscr{G}_{2}, p ; \mathscr{G}^{*}\right) \sim\left(\mathscr{G}_{1}, p ; \mathscr{G}\right) \\
\mathscr{G}_{1} \sim\left(\mathscr{G}_{2}, p_{g} ; \mathscr{G}_{0}\right)\end{array}\right\}$ & $\begin{array}{c}U\left(\mathscr{G}_{2}\right)-U\left(\mathscr{G}_{1}\right)=U\left(\mathscr{G}_{1}\right)-U\left(\mathscr{G}_{0}\right) \\
W^{+}\left(p_{g}\right)=0.5\end{array}$ & $\begin{array}{c}p=0.33 \\
\mathscr{G}^{*}=100 \\
\mathscr{G}=600 \\
\mathscr{G}_{0}=1,000\end{array}$ \\
\hline Step 2 & $L_{r} \in\left[L_{1}, 0\right]$ & $L_{r} \sim\left(L_{A}, p_{\ell} ; L_{B}\right)$ & $U\left(L_{r}\right)=0.5 U\left(L_{A}\right)+0.5 U\left(L_{B}\right)$ & $L_{1}=-100,000$ \\
\hline Step 3 & $\begin{array}{l}\ell \\
g \\
G_{s}\end{array}$ & $\begin{array}{l}L_{s} \sim(\ell, 0.5 ; 0) \\
0 \sim(g, 0.5 ; \ell) \\
G_{s} \sim(g, 0.5 ; 0)\end{array}$ & $\begin{array}{c}W^{-}(0.5) U(\ell)=-s \\
W^{+}(0.5) U(g)=s \\
U\left(G_{s}\right)=W^{+}(0.5) U(g)=s\end{array}$ & $s=0.25$ \\
\hline Step 4 & $G_{r} \in\left[0, G_{s}\right]$ & $G_{r} \sim\left(G_{A}, p_{g} ; G_{B}\right)$ & $U\left(G_{r}\right)=0.5 U\left(G_{A}\right)+0.5 U\left(G_{B}\right)$ & \\
\hline
\end{tabular}

*All monetary amounts are in French francs (FF).

the choices for these that we made in the experiment described in $\S 4$.

The first step of the elicitation determines two probabilities $p_{q}$ and $p_{\ell}$ for which $w^{+}\left(p_{q}\right)=1 / 2$ and $w^{-}\left(p_{\ell}\right)=1 / 2$. Both elicitations require three indifferences. Consider the elicitation of $p_{\ell}$. We will construct a sequence of losses $\mathscr{L}_{0}, \mathscr{L}_{1}$, and $\mathscr{L}_{2}$ that are equally spaced in terms of utility, i.e., $U\left(\mathscr{L}_{0}\right)-U\left(\mathscr{L}_{1}\right)=$ $U\left(\mathscr{L}_{1}\right)-U\left(\mathscr{L}_{2}\right)$. More specifically, the process starts by choosing a probability $p$ and three losses $\mathscr{L}^{*}, \mathscr{L}$, and $\mathscr{L}_{0}$, with $\mathscr{L}^{*}>\mathscr{L}>\mathscr{L}_{0}$. Then losses $\mathscr{L}_{1}$ and $\mathscr{L}_{2}$ are elicited such that a subject is indifferent between the prospects $\left(\mathscr{L}_{1}, p ; \mathscr{L}^{*}\right)$ and $\left(\mathscr{L}_{0}, p ; \mathscr{L}\right)$ and between the prospects $\left(\mathscr{L}_{2}, p ; \mathscr{L}^{*}\right)$ and $\left(\mathscr{L}_{1}, p ; \mathscr{L}\right)$. Because $\mathscr{L}^{*}>\mathscr{L}$, we must have $\mathscr{L}_{2}<\mathscr{L}_{1}<\mathscr{L}_{0}$. Under prospect theory, the indifferences $\left(\mathscr{L}_{i+1}, p ; \mathscr{L}^{*}\right) \sim\left(\mathscr{L}_{i}, p ; \mathscr{L}\right), i=0,1$, imply that

$$
\begin{array}{r}
U\left(\mathscr{L}_{i}\right)-U\left(\mathscr{L}_{i+1}\right)=\frac{1-w^{-}(p)}{w^{-}(p)}\left(U\left(\mathscr{L}^{*}\right)-U(\mathscr{L})\right), \\
i=0,1 .
\end{array}
$$

Because the expression on the right-hand side is constant, it follows that $U\left(\mathscr{L}_{0}\right)-U\left(\mathscr{L}_{1}\right)=U\left(\mathscr{L}_{1}\right)-$ $U\left(\mathscr{L}_{2}\right)$. Hence, $\mathscr{L}_{1}$ is a utility midpoint of $\mathscr{L}_{0}$ and $\mathscr{L}_{2}$. This procedure for eliciting utility midpoints was previously pointed out by Abdellaoui (2000) and by Köbberling and Wakker (2003). Having elicited $\mathscr{L}_{1}$ and $\mathscr{L}_{2}$, the probability $p_{\ell}$ is determined that makes the subject indifferent between $\mathscr{L}_{1}$ for sure and the prospect $\left(\mathscr{L}_{2}, p_{\ell} ; \mathscr{L}_{0}\right)$. This indifference implies that $w^{-}\left(p_{\ell}\right)=0.5 .^{2}$ The elicitation of $p_{g}$ is similar, except

\footnotetext{
${ }^{2}$ Under prospect theory, $U\left(\mathscr{L}_{1}\right)=w^{-}\left(p_{\ell}\right) U\left(\mathscr{L}_{2}\right)+\left(1-w^{-}\left(p_{\ell}\right)\right) U\left(\mathscr{L}_{0}\right)$. $\mathscr{L}_{1}$ being the utility midpoint of $\mathscr{L}_{0}$ and $\mathscr{L}_{2}$ immediately gives $w^{-}\left(p_{\ell}\right)=0.5$.
}

that now three monetary gains $\mathscr{G}_{0}>\mathscr{G}>\mathscr{G}^{*}$ are fixed beforehand.

In the second step of the elicitation, utility is determined on the loss domain by eliciting utility midpoints. As Table 2 shows, once $p_{\ell}$ is known the utility midpoint of any two losses $L_{A}$ and $L_{B}$ can be measured by eliciting just one indifference. Set $U\left(L_{1}\right)=-1$ for some $L_{1}<0$, which is allowed by the uniqueness properties of the utility function in prospect theory. Then the outcome $L_{0.5}$ is determined such that the subject is indifferent between $L_{0.5}$ for sure and the prospect $\left(L_{1}, p_{\ell} ; 0\right)$. Under prospect theory, this indifference implies that $U\left(L_{0.5}\right)=-0.5$. Then proceed to elicit $U$ on the interval $\left[L_{1}, 0\right]$. For example, by setting $L_{A}=L_{0.5}$ and $L_{B}=0$, we can elicit the outcome $L_{0.25}$ for which $U\left(L_{0.25}\right)=-0.25$.

In the third step, which is the crucial step in the measurement of loss aversion, utility on the loss domain is linked to utility on the gain domain by eliciting three indifferences. In the first indifference we take one of the outcomes that was elicited in step $2, L_{s}$, and determine the loss $\ell$ such that the subject is indifferent between $L_{s}$ and $(\ell, 0.5 ; 0)$. It follows that $w^{-}(0.5) U(\ell)=-s$. The second indifference determines the gain $g$ that makes the subject indifferent between 0 for sure and $(g, 0.5 ; \ell)$. Consequently, $w^{+}(0.5) U(g)=s$. The gain $G_{s}$ that the subject considers equivalent to the prospect $(g, 0.5 ; 0)$ then has utility $s$ and is the "mirror image" of $L_{s}$ in terms of utility.

The fourth and final step of the elicitation determines utility on the gain domain. As for losses, Table 2 shows that the probability $p_{q}$ allows measuring the utility midpoint of any two gains $G_{A}$ and $G_{B}$ through a single indifference. We start by determining the utility midpoint of $G_{s}$ and 0 and then proceed to determine utility on $\left[0, G_{s}\right]$. 


\section{Experiment}

\subsection{General Setup}

The aim of the experiment was to use the procedure outlined in $\$ 3$ to elicit utility and subsequently measure loss aversion under prospect theory. The subjects were 48 economics students at Ecole Normale Supérieure, Cachan, France ( $38 \%$ female, mean age 23). Subjects were paid FF100 (approximately $€ 16$ ) for their participation. Prior to the actual experiment, the experimental protocol was tested in pilot sessions.

The experiment was run on a computer. Responses were collected in personal interview sessions, which lasted about an hour on average. Subjects were told that there were no right or wrong answers and that they were allowed to take a break at any time during the interview. All responses were entered in the computer by the interviewer so that the subject could focus entirely on the experimental questions. Before the actual experiment started, subjects were given several practice questions.

To apply the method described in $\S 3$, we had to specify several parameters. The last column of Table 2 shows the specifications chosen. All outcomes were in French francs. To appreciate the significance of the amounts involved, we note that the participants in the experiment had a monthly income of FF 8,000 $(€ 1,250)$. We chose substantial monetary amounts to be able to detect curvature of the utility function. Over small intervals, utility is approximately linear (Wakker and Deneffe 1996).

Because substantial losses were involved, individual responses to the experimental questions were not played out for real. That is, we only used questions with hypothetical payoffs. Several studies have addressed the question whether response patterns differ between questions with hypothetical outcomes and questions with real outcomes (see Camerer and Hogarth 1999 and Hertwig and Ortmann 2001 for extensive reviews). The general conclusion from these studies is that the effect of real incentives varies across decision tasks. For the kind of task that we asked our subjects to perform, there appears to be no systematic difference in the general pattern of responses, although real incentives tend to reduce data variability and risk seeking.

Participants were not directly asked for the specific value (outcome or probability) leading to indifference. Instead, every indifference value was assessed by means of a series of binary choice questions. Each binary choice question corresponded to an iteration in a bisection process, which is described in Appendix B. A choice-based elicitation procedure was applied because previous studies have found that inferring indifferences from a series of choices leads to fewer inconsistencies than asking subjects directly for their indifference value (see Luce 2000 for a review).

\subsection{Details}

We elicited eleven points of the utility function on the loss domain, $L_{r}, r=0.015,0.031,0.062,0.093,0.125$, $0.25,0.375,0.5,0.625,0.75,0.875$, where $U\left(L_{r}\right)=-r$, and eight points of the utility function on the gain domain, $G_{r}, r=0.015,0.031,0.062,0.093,0.125$, $0.156,0.187,0.25$, where $U\left(G_{r}\right)=r$. We collected more data for losses than for gains to improve the operationalization of Kahneman and Tversky's (1979) definition of loss aversion. We deliberately elicited many points close to zero to be able to operationalize Köbberling and Wakker's (2005) definition of loss aversion.

The first display in Appendix A (see Figure A1) illustrates the typical choices subjects faced. Subjects had to choose one of the options A or B; indifference was not allowed. To facilitate responding, subjects were given the option to open a new window that added a scrollbar to the initial choice display. This option was only offered during the first iteration of the bisection process. Moving the scrollbar changed the value of the stimulus that we sought to elicit. At the one extreme of the range of values that the scrollbar allowed for, the subject could see that prospect A was clearly better than prospect $B$, at the other extreme he could see that prospect $B$ was clearly better than prospect A. By using the scrollbar, subjects became aware that there should be a value for which preferences between the two prospects switched. Once subjects understood this, the window with the scrollbar was closed and the program returned to the initial choice display. Many subjects kept using the scrollbar throughout the experiment. The scrollbar is illustrated in the second display in Appendix A (see Figure A2).

The first experimental choice was displayed twice to familiarize subjects with the task. After each choice, the subject was asked to confirm his answer. Indifference values were elicited in five iterations in steps 1,2 , and 4 of our method. In step 3 we used seven iterations. The pilot sessions had shown that these numbers of iterations were sufficient to obtain the indifference values with good precision. After the final iteration, subjects were asked whether the prospects were finely balanced for the elicited indifference value; when they indicated that this was not the case, the bisection process for this elicitation was started anew. This final question intended to minimize the impact of response errors.

We asked four questions to test for consistency. We established for each of the prospects $\left(G_{r}, p_{r} ; L_{r}\right)$, $r=0.031,0.0625,0.125,0.250$, the probability $p_{r}$ that made the subject indifferent between the risky prospect and receiving nothing. Equation (2) and the results derived before show that in each question we obtain $w^{+}\left(p_{r}\right)=w^{-}\left(1-p_{r}\right)$ and, because $w^{+}$and $w^{-}$ 
are strictly increasing, we should find the same indifference probability in all four questions.

We also tested consistency in another way. Recall that in the first step of the elicitation we constructed sequences $\left\{\mathscr{L}_{0}, \mathscr{L}_{1}, \mathscr{L}_{2}\right\}$ and $\left\{\mathscr{G}_{0}, \mathscr{G}_{1}, \mathscr{G}_{2}\right\}$ for which the difference in utility between successive elements is constant. We tested whether these equalities between utility differences were preserved in the elicitation of the utility function on the loss domain and on the gain domain in steps 2 and 4 of the elicitation procedure. In general, we did not know the utility of the $\mathscr{L}_{i}$ and $\mathscr{G}_{i}, i=0,1,2$, and we had to use linear interpolation to determine these. However, the quality of these interpolations was good, because the $\mathscr{L}_{i}$ and $\mathscr{G}_{i}$ were generally concentrated near zero where we had many observations.

\subsection{Analysis}

We determined for each subject the shape of the utility function on the gain domain and on the loss domain by looking at the evolution of the slope of the utility function at various points. Two elicited losses $L_{r}$ and $L_{r^{\prime}}$ (gains $G_{r}$ and $G_{r^{\prime}}$ ) are adjacent if $L_{r}>L_{r^{\prime}}\left(G_{r}>G_{r^{\prime}}\right)$ and there is no elicited loss (gain) in between. Define by $S_{L}^{\uparrow}(r)$ the slope of the segment linking $\left(L_{r}, U\left(L_{r}\right)\right)$ and $\left(L_{r^{\prime}}, U\left(L_{r^{\prime}}\right)\right)$, where $L_{r}$ and $L_{r^{\prime}}$ are adjacent. Similarly, $S_{L}^{\downarrow}(r)$ is defined as the slope of the segment linking $\left(L_{r^{\prime \prime}}, U\left(L_{r^{\prime \prime}}\right)\right)$ and $\left(L_{r}, U\left(L_{r}\right)\right)$, where $L_{r^{\prime \prime}}$ and $L_{r}$ are adjacent. $S_{G}^{\uparrow}(r)$ and $S_{G}^{\downarrow}(r)$ are defined similarly for adjacent gains. Let $\Delta S_{L}(r)=$ $S_{L}^{\downarrow}(r)-S_{L}^{\uparrow}(r)$ denote the variation of the slope around $L_{r}$ when moving toward 0. Similarly $\Delta S_{G}(r)=S_{G}^{\downarrow}(r)-$ $S_{G}^{\uparrow}(r)$ designates the variation of the slope around $G_{r}$ when moving away from 0 . It is easily verified that $\Delta S_{i}(r), i=G, L$, positive [negative, zero] corresponds to convex [concave, linear] utility.

We obtained 11 values of $\Delta S_{L}(r)$ and seven values of $\Delta S_{G}(r)$ for each subject. To account for response error, we classified a subject's utility on the loss domain as convex (concave) if at least seven out of 11 values of $\Delta S_{L}(r)$ were positive (negative). We classified a subject's utility on the gain domain as convex (concave) if at least four out of seven values of $\Delta S_{G}(r)$ were positive (negative). These cut-off values are admittedly arbitrary. They were selected for two reasons. First, empirical studies have observed that reversal rates of $1 / 3$ are common in choice tasks and, second, other studies measuring the utility for gains and the utility for losses under prospect theory used similar criteria (Fennema and van Assen 1998, Abdellaoui 2000, Etchart-Vincent 2004). Results for other cut-off values can be found in the e-companion. ${ }^{3}$ In addition, we

\footnotetext{
${ }^{3}$ An electronic companion to this paper is available as part of the online version that can be found at http://mansci.journal.informs. org/.
}

also provided a classification of the subjects based on their estimated power coefficients, which is described below and which does not depend on arbitrary cut-off values.

To smoothen out response errors, we also analyzed the data assuming specific parametric forms for utility. We examined three parametric forms: the power family, the exponential family, and the expo-power family. The expo-power family was introduced by Abdellaoui et al. (2007) and is a variation of a twoparameter family proposed by Saha (1993). Because the results under the three parametric families were similar and we observed no significant differences in goodness of fit, we will only report the results for the power family. Let $x_{\ell}=-L / L_{1}, L \in\left[-L_{1}, 0\right], x_{g}=$ $G / G_{0.25}, G \in\left[0, G_{0.25}\right]$. The power family is defined on the gain domain by $0.25 *\left(x_{q}\right)^{\alpha}$ and on the loss domain by $-\left(x_{\ell}\right)^{\beta}$. For gains (losses), the power function is concave (convex) if $\alpha<1(\beta<1)$, linear if $\alpha=1(\beta=$ $1)$, and convex (concave) if $\alpha>1(\beta>1)$. Nonlinear least squares was used to estimate the parameters $\alpha$ and $\beta$.

We explain next how we operationalized the various definitions of loss aversion described in $\$ 2$ and how we measured loss aversion at the individual level. To test for loss aversion in the Kahneman and Tversky (1979) sense, we computed $-U\left(-G_{r}\right) / U\left(G_{r}\right)$ for each of the eight amounts $G_{r}$ that we had elicited. The $U\left(-G_{r}\right)$ usually had to be determined through linear interpolation. As we had many observations for utility on the loss domain, the approximation by linear interpolation was in general good. Because we had eight observations of $G_{r}$, we could compute for most subjects eight values of the loss aversion coefficient $-U\left(-G_{r}\right) / U\left(G_{r}\right)$. For five subjects, $G_{0.25}$ exceeded- $L_{1}$ and we could, therefore, not compute $U\left(-G_{0.25}\right)$. For these subjects, we replaced this missing observation by taking $L_{1}$ and determined $U\left(-L_{1}\right)$. A subject was classified as loss averse if at least six out of eight values of the loss aversion coefficient exceeded one, as loss neutral if at least six values were equal to one, and as gain seeking if at least six values were less than one. We used a more stringent cut-off value in the classification of loss aversion than in the classification of utility curvature because the sequential structure of our procedure made it more likely that subjects could be classified. For example, if $G_{0.25}$ was much larger than $-L_{0.25}$ then all the other $G_{r}$ will likely also be larger than the $-L_{r}$. For this reason we also considered the results without allowance for response error.

To operationalize Neilson's (2002) definition that loss aversion holds if $U(-x) /-x>U(y) / y$ for all positive $x$ and $y$, we computed for each subject the values $U\left(L_{r}\right) / L_{r}$ and $U\left(G_{r}\right) / G_{r}$ for each $L_{r}$ and each $G_{r}$ 
that had been elicited. To allow for response error, a subject was loss averse if the second smallest value of the $U\left(L_{r}\right) / L_{r}$ exceeded the second largest value of the $U\left(G_{r}\right) / G_{r}$ and gain seeking if the second smallest value of the $U\left(G_{r}\right) / G_{r}$ exceeded the second largest value of the $U\left(L_{r}\right) / L_{r}$. The coefficient of loss aversion was computed as the ratio of the second smallest value of $U\left(L_{r}\right) / L_{r}$ over the second largest value of the $U\left(G_{r}\right) / G_{r}$. We also analyzed the results without accounting for response error and then we used the minimum instead of the second smallest value and the maximum instead of the second largest value.

Wakker and Tversky's (1993) definition of loss aversion, $U^{\prime}(-x) \geq U^{\prime}(x)$ for all positive $x$, was operationalized by defining for each elicited $G_{r}$

$$
U^{\prime}\left(G_{r}\right)=\frac{1}{2} *\left(S_{G}^{\downarrow}(r)+S_{G}^{\uparrow}(r)\right)
$$

and

$$
U^{\prime}\left(-G_{r}\right)=S_{L}^{\downarrow}(r)
$$

if $L_{s^{\prime}}<-G_{r}<L_{s}$ and $L_{s}$ and $L_{s^{\prime}}$ are adjacent, and by defining

$$
U^{\prime}\left(-G_{r}\right)=\frac{1}{2} *\left(S_{L}^{\downarrow}(r)+S_{L}^{\uparrow}(r)\right)
$$

if $-G_{r}=L_{s}$.

In general, this procedure resulted in eight observations per subject. For the five subjects for whom $G_{0.25}$ exceeded $-L_{1}$, we could not compute $U^{\prime}\left(-G_{0.25}\right)$. Instead, we computed $U^{\prime}\left(L_{1}\right) / U^{\prime}\left(-L_{1}\right)$. We classified a subject as loss averse if at least six out of eight values of the loss aversion coefficient exceeded one, as loss neutral if at least six values were equal to one, and as gain seeking if at least six values were less than one.

The definition of Bowman et al. (1999), that loss aversion holds if $U^{\prime}(-x) \geq U^{\prime}(y)$ for all positive $x$ and $y$, was operationalized by computing $U^{\prime}\left(G_{r}\right)$ as in Equation (4a) and $U^{\prime}\left(L_{r}\right)$ as $1 / 2 *\left(S_{L}^{\downarrow}(r)+S_{L}^{\uparrow}(r)\right)$ for each $G_{r}$ and each $L_{r}$ that had been elicited. Individuals were classified as loss averse if the second smallest value of the $U^{\prime}\left(L_{r}\right)$ exceeded the second largest value of the $U^{\prime}\left(G_{r}\right)$ and as gain seeking if the second smallest value of the $U^{\prime}\left(G_{r}\right)$ exceeded the second largest value of the $U^{\prime}\left(L_{r}\right)$. A loss aversion coefficient was computed as the ratio of the second smallest value of the $U^{\prime}\left(L_{r}\right)$ over the second largest value of the $U^{\prime}\left(G_{r}\right)$. We used the minimum and the maximum instead of the second smallest and the second largest value when response error was not taken into account.

Finally, the definition of Köbberling and Wakker (2005) was operationalized by computing each subject's coefficient of loss aversion as the ratio of $U\left(L_{0.015}\right) / L_{0.015}$ over $U\left(G_{0.015}\right) / G_{0.015}$, which is equal to $G_{0.015} / L_{0.015}$. If the coefficient of loss aversion exceeded one, the subject was classified as loss averse; if it was equal to one, he was loss neutral; and if it was less than one, he was gain seeking. Of the definitions considered, only Köbberling and Wakker's definition is exhaustive, in the sense that every individual could always be classified. In all other definitions it is possible that some subjects were left unclassified.

\section{Results}

The results of the consistency tests were mixed. We could not reject the hypotheses that $U\left(\mathscr{L}_{0}\right)-U\left(\mathscr{L}_{1}\right)=$ $U\left(\mathscr{L}_{1}\right)-U\left(\mathscr{L}_{2}\right)(p=0.196$ by a binomial test, $p=0.061$ by a paired $t$-test) and that $U\left(\mathscr{G}_{2}\right)-U\left(\mathscr{G}_{1}\right)=U\left(\mathscr{G}_{1}\right)-$ $U\left(\mathscr{G}_{0}\right)(p=0.170$ by a binomial test, $p=0.192$ by a paired $t$-test). The hypothesis that $p_{0.25}=p_{0.125}=$ $p_{0.0625}=p_{0.031}$ was rejected, however $(p=0.001$, Friedman test). The median (mean) values of $p_{0.25}, p_{0.125}$, $p_{0.0625}$, and $p_{0.031}$ were $0.64(0.64), 0.59(0.60), 0.60(0.58)$, and 0.52 (0.56). Paired comparisons showed significant differences between $p_{0.25}$ and the other $p_{i}$, but not between $p_{0.125}, p_{0.0625}$, and $p_{0.031}$.

Appendix $C$ shows for each subject the elicited probabilities $p_{\ell}$ and $p_{g}$, the estimated coefficients of the power function, and the values of the five loss aversion coefficients.

\subsection{The Utility for Gains and Losses}

The median values of $p_{\ell}$ and of $p_{g}$ were equal to 0.59 and 0.60 , respectively. Because $w^{-}\left(p_{\ell}\right)=w^{+}\left(p_{g}\right)=1 / 2$, our data reveal underweighting of probability around 0.60. This is consistent with other findings in the literature. Tversky and Kahneman (1992) found $w^{+}(0.65)=1 / 2$ and $w^{-}(0.57)=1 / 2$; Abdellaoui (2000) found $w^{+}(0.65)=1 / 2$ and $w^{-}(0.53)=1 / 2$. In contrast with Tversky and Kahneman (1992) and Abdellaoui (2000), we found no difference in probability weighting for gains and for losses (paired $t$-test, $p=0.278$ ). At the individual level we also found clear evidence of underweighting of probabilities: For $79 \%$ of the subjects $p_{g}$ exceeded $1 / 2$ and for $73 \%$ of the subjects $p_{\ell}$ exceeded $1 / 2$.

Figure 1 displays the utility function for gains and losses based on the median data. The data are consistent with prospect theory's hypothesis that utility is convex for losses and concave for gains. Figure 1 also displays the utility function when the data are analyzed under the assumption that expected utility holds, i.e., assuming that there is no probability weighting, $w^{+}(p)=w^{-}(p)=p$ for all $p$. The figure shows that under expected utility, utility is more convex on the loss domain and more concave on the gain domain than under prospect theory.

The conclusions drawn at the aggregate level were confirmed when we looked at the individual data. 
Figure 1 The Utility for Gains and Losses Under Prospect Theory and Expected Utility Based on the Median Data

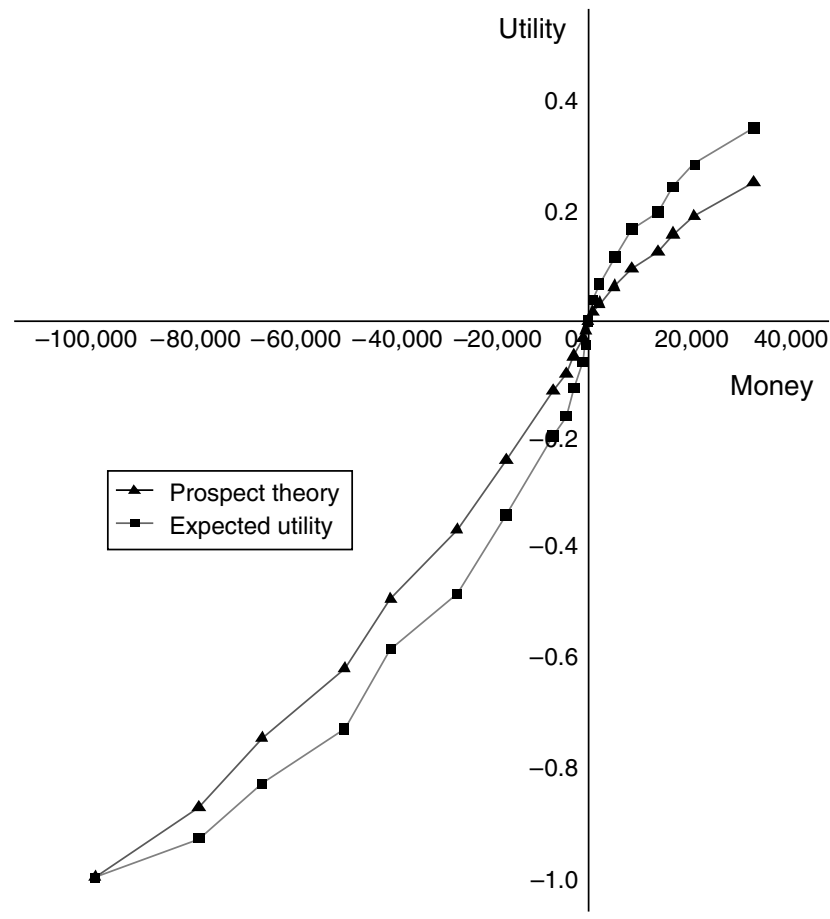

Table 3 shows the classification of subjects according to the shape of their utility function. The most common pattern is S-shaped utility: convex utility on the loss domain and concave utility on the gain domain. We found both more concavity for gains and more convexity for losses and, hence, more support for prospect theory than previous studies (Tversky and Kahneman 1992, Fennema and van Assen 1998, Abdellaoui 2000, Etchart-Vincent 2004, Schunk and Betsch 2006, Booij and van de Kuilen 2006). Only one subject behaved according to the traditional assumption in economics of concave utility both for gains and for losses.

Figure 2 displays the estimated power function for the median data. The power coefficients were 0.75 for gains and 0.74 for losses. Both coefficients differed significantly from 1 . The power function fitted the median data well: the adjusted $R^{2}$ exceeded 0.99 both in the estimation for gains and in the estimation for

Table 3 Classification of Subjects According to the Shape of Their Utility Function

\begin{tabular}{lcccc}
\hline & \multicolumn{3}{c}{ Losses } & \\
\cline { 2 - 4 } Gains & Concave & Convex & Mixed & Total \\
\hline Concave & 1 & 26 & 7 & 34 \\
Convex & 3 & 6 & 3 & 12 \\
Mixed & 0 & 1 & 1 & 2 \\
Total & 4 & 33 & 11 & 48 \\
\hline
\end{tabular}

Figure 2 Parametric Fit of the Power Function Based on the Median Data

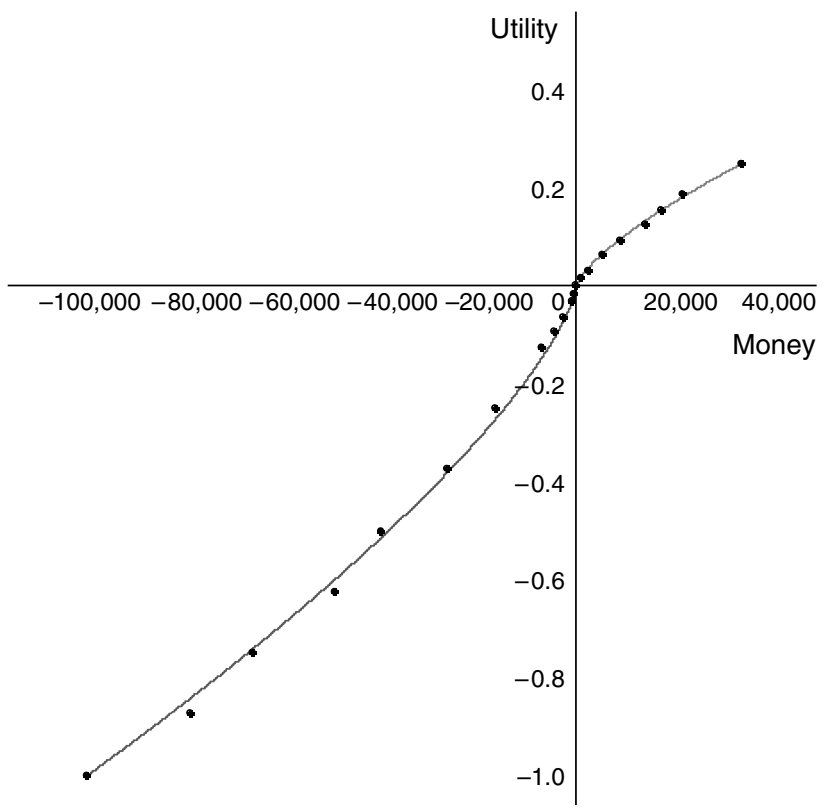

losses. The goodness of fit is illustrated in Figure 2. The median data points lie on or close to the fitted power function.

Table 4 shows the results from the parametric estimations of the power function at the individual level. The parametric estimations confirm the conclusions drawn above: Utility was concave on the gain domain and convex on the loss domain. The fit of the estimations was very good with median individual adjusted $R^{2 \prime}$ s of 0.99 both for gains and for losses.

We also fitted for each subject a power function to the expected utilities. Table 4 shows that, by ignoring probability weighting, expected utility led to utility functions that were more concave on the gain domain and more convex on the loss domain than under prospect theory. In the parametric estimation, we also found a more pronounced S-shaped utility function than previous studies (Tversky and Kahneman 1992, Fennema and van Assen 1998, Abdellaoui 2000, Etchart-Vincent 2004, Schunk and Betsch 2006, Booij and van de Kuilen 2006).

\begin{tabular}{|c|c|c|c|c|}
\hline \multirow[t]{3}{*}{ Table 4} & \multicolumn{4}{|c|}{$\begin{array}{l}\text { Summary of Individual Parametric Fittings of Utility for } \\
\text { Gains }\left(U\left(x_{g}\right)=X_{g}^{\alpha}\right) \text { and Losses }\left(U\left(X_{\ell}\right)=-\left(x_{\ell}\right)^{\beta}\right)\end{array}$} \\
\hline & \multicolumn{2}{|c|}{ Gains } & \multicolumn{2}{|c|}{ Losses } \\
\hline & PT & EU & PT & EU \\
\hline Mean & 0.859 & 0.654 & 0.798 & 0.677 \\
\hline Median & 0.717 & 0.576 & 0.725 & 0.567 \\
\hline St. dev. & 0.394 & 0.341 & 0.401 & 0.370 \\
\hline IQR & {$[0.61,1.008]$} & {$[0.46,0.78]$} & {$[0.60,0.83]$} & {$[0.46,0.82]$} \\
\hline
\end{tabular}

Note. IQR stands for the interquartile range, PT for prospect theory, EU for expected utility. 
We used the data from the parametric fittings to classify subjects according to the shape of their utility function. Thirty-six out of 48 subjects had concave utility on the gain domain and 40 subjects had convex utility on the loss domain. Thirty-one subjects had an S-shaped utility function: convex on the loss domain and concave on the gain domain. Only five subjects had a utility function that was everywhere concave. The dominant pattern was clearly convex utility on the loss domain and concave utility on the gain domain.

\subsection{Loss Aversion}

Figure 3 displays the relationship between the median of $G_{r}$ and the median of $-L_{r}, r=0.015$, $0.031,0.063,0.093,0.125,0.25$, i.e., the relationship between gains and losses that have the same utility in absolute terms. The dashed line corresponds to equality between median gains and median losses that have the same utility in absolute terms. There were six pairs $\left(G_{r}, L_{r}\right)$ that we could compare. We found that $-L_{r}<G_{r}$ in each comparison, which can be seen from Figure 3 by observing that all pairs lie below the dashed line. All differences between $-L_{r}$ and $G_{r}$ were significant by the paired $t$-test except for the difference between $-L_{0.015}$ and $G_{0.015}(p=0.186)$. This latter difference was, however, significant $(p=$ 0.003 ) by a binomial test, which compared the proportion of subjects for whom $-L_{0.015}>G_{0.015}$ with the proportion of subjects for whom $-L_{0.015}<G_{0.015}$.

Figure 3 shows that the relationship between gains and losses of the same absolute utility was close to linear. The function $G_{r}=1.928 *\left(-L_{r}\right)^{1.005}$ gave an excellent fit of the data (adjusted $R^{2}=1$ ). The power coefficient was not significantly different from 1 ,

Figure 3 The Relationship Between Median Gains and Median Losses with the Same Absolute Utility

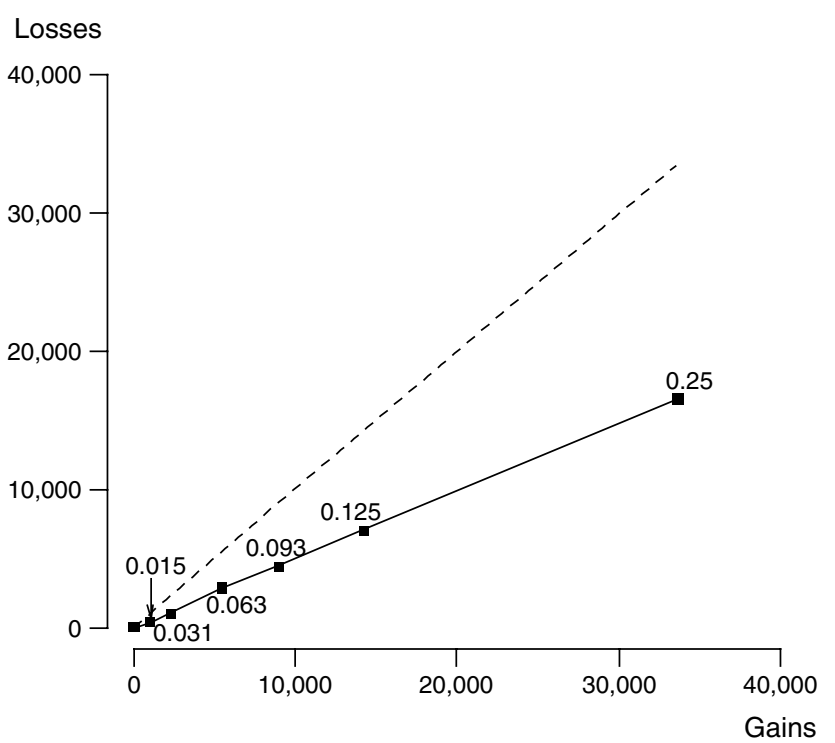

which suggests a linear relationship between gains and losses of the same absolute utility, with gains being almost twice as large as losses.

Recall that Kahneman and Tversky (1979) defined loss aversion as $-U(-x)>U(x)$ for all $x>0$. Our finding that $-L_{r}<G_{r}$ in each comparison implies, in combination with $-U\left(L_{r}\right)=U\left(G_{r}\right)$, that $-U\left(-G_{r}\right)>$ $U\left(G_{r}\right)$. Hence, using Kahneman and Tversky's (1979) definition, we found support for loss aversion at the aggregate level.

Table 5 displays the results of the individual analysis of loss aversion. Columns 3 through 5 show the classification of the subjects both when we allow for response error and, in parentheses, when response error is not taken into account. Table 5 clearly shows that it matters which definition of loss aversion is adopted. According to the definitions of Kahneman and Tversky (1979) and Köbberling and Wakker (2005), a large majority of our subjects was loss averse regardless of whether response error was taken into account. The definitions proposed by Neilson (2002) and Bowman et al. (1999) are strict and by these only a minority of subjects was loss averse. The definition of Wakker and Tversky (1993) lies somewhere in between. We found more loss aversion at the individual level than Schmidt and Traub (2002) and than Bleichrodt and Pinto (2002).

The final two columns of Table 5 show the means and the medians of the individual loss aversion coefficients. A table with all individual loss aversion coefficients can be found in the e-companion. For the definitions of Kahneman and Tversky (1979) and Wakker and Tversky (1993) where we had eight observations per subject, we determined the individual loss aversion coefficient by taking the median of these eight observations. The results based on the mean of the eight observations were similar. The table shows that the median loss aversion coefficient under the definition of Kahneman and Tversky (1979) is somewhat lower than the median values obtained by Tversky and Kahneman (1992) and by Bleichrodt et al. (2001), see Table 1. Our median estimate of the loss aversion coefficient under the definition of Wakker and Tversky (1993) is in between the values obtained by Schmidt and Traub (2002) and by Pennings and Smidts (2003). It is much lower than the value in Fishburn and Kochenberger (1979).

Under the definition of Kahneman and Tversky (1979), both the mean (from 2.64 to 2.04) and the median (from 1.97 to 1.69) value of the ratio $-U\left(-G_{r}\right) / U\left(G_{r}\right)$ decreased with the size of the gains and losses involved. A similar finding was reported by Bleichrodt and Pinto (2002), who observed in the health domain that the degree of loss aversion decreased with the size of the outcomes. Under the definition of Wakker and Tversky (1993), we did not 
Table 5 Results Under the Various Definitions of Loss Aversion

\begin{tabular}{lcccccc}
\hline Method & Coefficient & Loss averse & Gain seeking & Loss neutral & Mean [St. dev.] & Median [IQR] \\
\hline Kahneman and Tversky (1979) & $\frac{-U\left(-G_{r}\right)}{U\left(G_{r}\right)}$ & $39(31)$ & $8(3)$ & $0(0)$ & $2.04[1.40]$ & $1.69[1.19,2.34]$ \\
Neilson (2002) & $\frac{\min \left(U\left(L_{r}\right) / L_{r}\right)}{\max \left(U\left(G_{r}\right) / G_{r}\right)}$ & $15(12)$ & $2(1)$ & $0(0)$ & $1.07[1.17]$ & $0.74[0.39,1.13]$ \\
Wakker and Tversky (1993) & $\frac{U^{\prime}\left(-G_{r}\right)}{U^{\prime}\left(G_{r}\right)}$ & $30(16)$ & $6(1)$ & $0(0)$ & $1.71[0.97]$ & $1.48[1.06,2.16]$ \\
Bowman et al. (1999) & $\frac{\min U^{\prime}\left(L_{r}\right)}{\max U^{\prime}\left(G_{r}\right)}$ & $13(6)$ & $1(0)$ & $0(0)$ & $0.74[0.69]$ & $0.43[0.32,1.07]$ \\
Köbberling and Wakker (2005) & $\frac{G_{0.015}}{L_{0.015}}$ & 35 & 12 & 1 & $8.27[15.24]$ & $2.54[0.98,6.04]$ \\
\hline
\end{tabular}

Note. The numbers in parentheses refer to the case where no response error is allowed.

observe this effect; the degree of loss aversion varied, but was not related to the size of the outcomes.

\subsection{Reflection}

Our aggregate findings suggest that the curvature of utility on the gain domain is close to the curvature of utility on the loss domain (see Table 4 and Figure 2). This is consistent with Kahneman and Tversky's (1979) reflection effect, which says that preferences for prospects involving only losses are the mirror image of preferences for prospects involving only gains. Obviously, support for reflection is important for practical decision analysis because it implies that fewer data have to be collected as utility on the loss domain can be inferred from utility on the gain domain and vice versa. It is also interesting from a theoretical point of view because support for reflection would indicate that a common psychophysical response to an increasing amount of money gained or lost underlies utility on the gain domain and on the loss domain.

At the individual level we found less support for reflection, however. Figure 4 displays the relationship between the individual estimates for the power coefficient for gains and for the power coefficient for losses. The straight line corresponds to the pattern predicted by reflection. Points inside the dotted box are subjects who exhibit concave utility on the gain domain and convex utility on the loss domain. The figure shows that there is no clear relationship between the power coefficients. The Pearson correlation coefficient between the power coefficients was 0.389 , which differed significantly from $1(p<0.001)$, the case of perfect correlation predicted by reflection, but also from $0(p=0.006)$, the case of no relationship. Kendall's tau and Spearman's rank correlation coefficient were equal to 0.117 and 0.164 . They differed significantly from 1 ( $p<0.001$ in both tests), but not from 0 ( $p>0.10$ in both tests).

We also assessed how bad it is to measure loss aversion assuming reflection. We assumed power utility both for gains and for losses and imposed for each subject the power coefficient for gains on the utility for losses. Then we determined the implied losses and used these to operationalize the various definitions of loss aversion. For example, to operationalize the definition of Köbberling and Wakker (2005) we determined $L_{0.015}=-L_{1} *(0.015)^{1 / \alpha}$ where $\alpha$ is the power coefficient for gains. Assuming reflection led to the misclassification of a considerable number of subjects (i.e., subjects who were loss averse were now classified as loss neutral or gain seeking or were left unclassified): 16 out of 48 subjects (33.3\%) were misclassified according to Kahneman and Tversky's (1979) definition, 18 (37.5\%) according to Köbberling and Wakker's (2005) definition, and 17 (35.4\%) according to Wakker and Tversky's (1993) definition. For the Neilson (2002) and Bowman et al. (1999) definitions, these numbers were lower, nine and eight respectively, but few subjects could be classified by these definitions anyhow.

Figure 4 The Relationship Between Indivdual Power Coefficients for Gains and for Losses

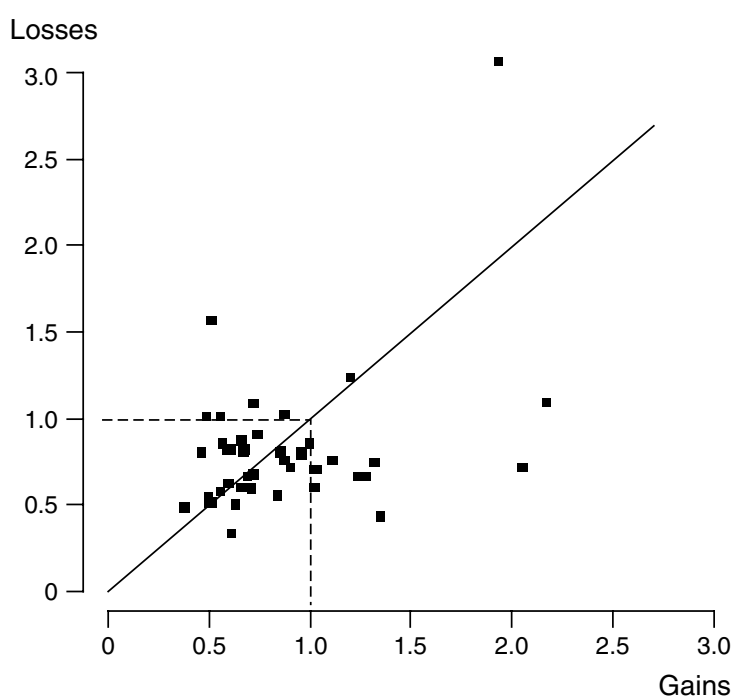


Table 6 Difference Between Observed Loss Aversion and Loss Aversion Predicted Under Reflection

\begin{tabular}{lcccccccc}
\hline & \multicolumn{2}{c}{ Kahneman and Tversky (1979) } & & \multicolumn{2}{c}{ Wakker and Tversky (1993) } & & & \\
& Mean & Med & Neilson (2002) & Mean & Med & Bowman et al. (1999) & Köbberling and Wakker (2005) \\
\hline Median & 0.11 & 0.09 & 0.03 & 0.17 & -0.02 & 0.00 & -0.13 \\
IQR & {$[-0.72,0.77]$} & {$[-0.57,0.49]$} & {$[-0.02,0.21]$} & {$[-0.32,0.44]$} & {$[-0.55,0.20]$} & {$[-0.07,0.08]$} & {$[-2.93,2.81]$} \\
\hline
\end{tabular}

Table 6 shows the median values of the individual differences between the observed loss aversion coefficient and the loss aversion coefficient predicted under reflection and their interquartile ranges. At the aggregate level assuming reflection does not lead to a major distortion in the measured loss aversion coefficients as the median values are all close to zero. The difference was only significant for Neilson's definition ( $p=0.012$ by Wilcoxon's test). The interquartile ranges reflect the fact that at the individual level considerable distortions arise. This is in particular true for Köbberling and Wakker's (2005) measure of loss aversion. A table showing all individual differences between the observed values of the loss aversion coefficients and those predicted under reflection is in the e-companion.

\section{Conclusion}

Tversky and Kahneman (1992, p. 311) noted that "[t]he estimation of a complex choice model, such as ... prospect theory, is problematic. If the functions associated with the theory are not constrained, the number of estimated parameters for each subject is too large." We have shown that, contrary to the conjecture of Tversky and Kahneman, the estimation of utility in prospect theory is not restrictively complicated and can be performed without imposing parametric assumptions. In combination with the methods described in Abdellaoui (2000) and Bleichrodt and Pinto (2000) to measure probability weighting, our method allows for a complete parameter-free elicitation of prospect theory. The availability of nonparametric methods to elicit prospect theory is important for applications and tests of prospect theory.

Our method for measuring utility is based on the elicitation of utility midpoints. As noted in $\S 3$, Köbberling and Wakker (2003) pointed out before how utility midpoints can be elicited. A disadvantage of their procedure is that there is no control over the endpoints: In Table 2 we are not free to select $\mathscr{L}_{2}$. Like our method, Vind (2003) suggested a method to elicit utility midpoints for given endpoints. Instead of assuming prospect theory, Vind assumed a general additive representation, which is not directly applicable to prospect theory. Our method is more efficient than Vind's method in that we need fewer measurements to elicit a given number of utility midpoints.
The elicitation of $p_{\ell}$ (or $p_{q}$ ) requires three measurements. Once $p_{\ell}$ (or $p_{q}$ ) is known, we need just one measurement to determine a utility midpoint. Vind's (2003) method, on the other hand, requires three measurements per utility midpoint.

Our method is sequential and involves chained measurements. A potential danger with chained measurements is propagation of response error. Both Bleichrodt and Pinto (2000) and Abdellaoui et al. (2005) examined in detail the effect of error propagation on chained measurements and found that the effect was negligible and did not affect their conclusions. The elicitation methods that were used in these two studies were similar to those used in our study and, hence, we are inclined to conclude that error propagation will not have distorted our findings. Blavatskyy (2006) showed theoretically that our elicitation method is optimally efficient in the sense that it minimizes the effect of error on the inferred utility function relative to other elicitation procedures.

Our experimental findings are in keeping with the assumptions made by prospect theory. We found that utility is convex for losses and concave for gains. We observed more support for prospect theory than previous studies did. It is not entirely clear why this is the case. We used outcomes of a larger size than Tversky and Kahneman (1992), Fennema and van Assen (1998), and Abdellaoui (2000), which suggests that the size of the outcomes may be important. On the other hand, Etchart-Vincent (2004), who used losses of similar size as we did, found less convexity for losses. Another reason why our results may be different is that we used a different method, primarily based on the elicitation of certainty equivalents. Fennema and van Assen (1998), Abdellaoui (2000), and Etchart-Vincent (2004) all used the trade-off method. The trade-off method involves four instead of three outcomes and, in contrast with our method, imposes no bound on the largest loss involved. Hence, the trade-off method is likely to invoke more demanding cognitive processes. On the other hand, the parametric estimates of Tversky and Kahneman (1992), which were different from ours, were also based on certainty equivalences. Abdellaoui et al. (2007) observed for gains no significant differences between trade-off measurements and certainty equivalence measurements under prospect theory. Whether their conclusions also hold for losses is an open question. 
One contribution of using nonparametric elicitation methods is that they may validate reasonable functional forms and thus give license for certain types of parametric estimation procedures. The advantage of using parametric estimation methods over nonparametric elicitation methods is that response errors will be smoothened out and that relatively good estimates can be obtained with a smaller set of prospects. We found that a power function fits our data very well, suggesting that this function might be used in future studies that aim to estimate prospect theory's utility function.

We found clear evidence of loss aversion both at the aggregate and at the individual level. The degree of loss aversion varied with the definition of loss aversion used. The elicitation technique of this paper does not commit to a particular definition of loss aversion: it is "loss aversion definition-free" so to speak. Two kinds of definition have been proposed in the literature, global definitions and a local definition. Kahneman and Tversky (1979), Wakker and Tversky (1993), Bowman et al. (1999), and Neilson (2002) have proposed global definitions of loss aversion. To operationalize their definitions they need to scan the specific utility domain under study for any loss aversion measurement. The local definition of loss aversion, informally proposed by Benartzi and Thaler (1995) and formalized by Köbberling and Wakker (2005), measures loss aversion at the reference point and provides a natural "single-numbered" measurement index for loss aversion. In this definition loss aversion becomes manifest in the kink of the utility function at the reference point.

The central question that must be answered in choosing between local and global definitions of loss aversion is whether loss aversion is a property that can be defined independently of utility curvature. In the local definition of Köbberling and Wakker (2005) loss aversion does not depend on utility curvature and their definition allows a decomposition of risk attitude into three distinct components: utility curvature, probability weighting, and loss aversion. Global definitions have the drawback that loss aversion cannot be separated from utility curvature and, hence, a clear separation of risk attitude into distinct components is generally impossible. Our findings show that the distinction between global measures and local measures is not trivial, because for most subjects the curvature of utility on the gain domain was clearly different from the curvature of utility on the loss domain. The latter observation also revealed a drawback of global measures of loss aversion: Because loss aversion can be measured at different points it can become difficult to determine unambiguously what the subject's attitude toward losses is. Except for Kahneman and Tversky's (1979) definition, the global measures indeed left many subjects unclassified. This was particularly true for the measures proposed by Neilson (2002) and Bowman et al. (1999). These definitions may be useful for theorizing, but for empirical purposes they seem too strict.

It is perhaps inevitable that when a new concept, like loss aversion, is introduced, disagreement exists about its precise meaning and definition. Now that prospect theory seems to be emerging as the dominant descriptive theory of decision under risk, and our findings appear to underline this role, the need for a common definition of loss aversion becomes more urgent. Fully resolving the debate about how to define loss aversion is beyond the scope of this paper. We hope, however, that our findings will contribute to this debate.

\section{Electronic Companion}

An electronic companion to this paper is available as part of the online version that can be found at http://mansci.journal.informs.org/.

\section{Acknowledgments}

Manel Baucells, Enrico Diecidue, Craig Fox, Antonio Villasis, Peter Wakker, George Wu, Horst Zank, an associate editor, and three anonymous referees gave many helpful comments on previous drafts. The second author's research was made possible by a grant from The Netherlands Organization for Scientific Research (NWO).

\section{Appendix A. Display of the Experimental Questions}

The questions in the first step of the elicitation procedure were displayed in the following manner (see Figure A1).

Figure A2, which was one of the questions in the second step of our experimental procedure, illustrates the use of the scrollbar.

\section{Appendix B. The Bisection Method}

The bisection method used to generate the iterations is illustrated in Table A1 for $\mathscr{L}_{1}$ and $L_{0.0625}$. The prospect that is chosen in each iteration is shown in bold. Table A1 shows that only the outcome that we sought to elicit varied. Depending on the choice in an iteration, this outcome was increased or decreased. The size of the change was always half the size of the change in the previous question under the restrictions that the resulting outcome should be a multiple of 10 and that the resulting probability should be a multiple of 0.01 . Otherwise the value was set equal to the closest multiple of 10 or of 0.01 . The method resulted in an interval within which the indifference value should lie. The midpoint of this interval was taken as the indifference value. For example, in Table A1 the indifference value for $L_{0.0625}$ should lie between $-4,180$ and $-4,560$ and we took $-4,370$ as the indifference value.

Starting values in the iterations were generally chosen so that prospects had equal expected value. Exceptions were $\mathscr{L}_{1}, \mathscr{L}_{2}, \mathscr{G}_{1}$, and $\mathscr{G}_{2}$, whose starting values were $\mathscr{L}_{0}+3,000$, $\mathscr{L}_{1}+3,000, \mathscr{G}_{0}+3,000$, and $\mathscr{G}_{1}+3,000$. 


\section{Figure A1 Display of the Prospects}

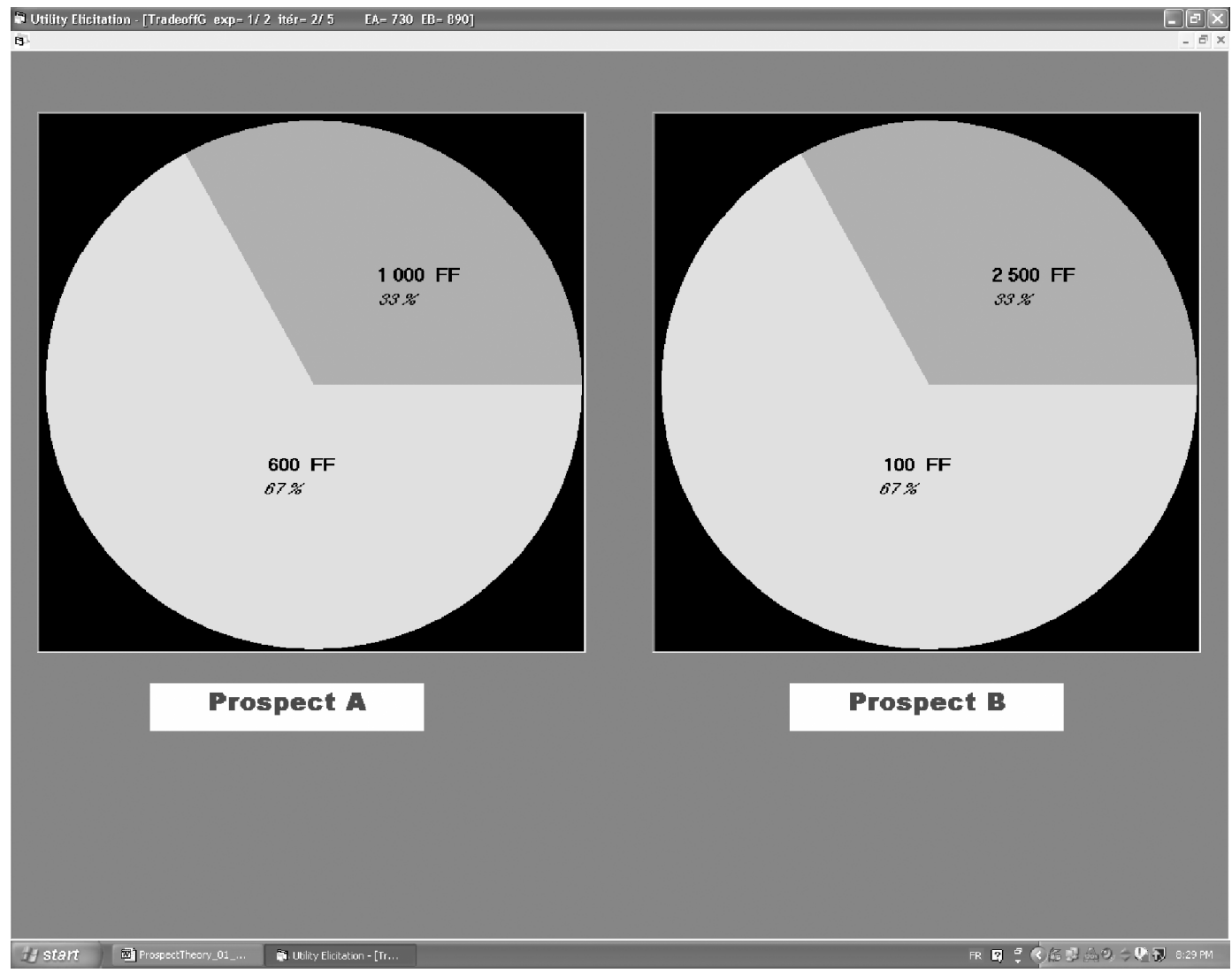

Figure A2 Illustration of the Scrollbar

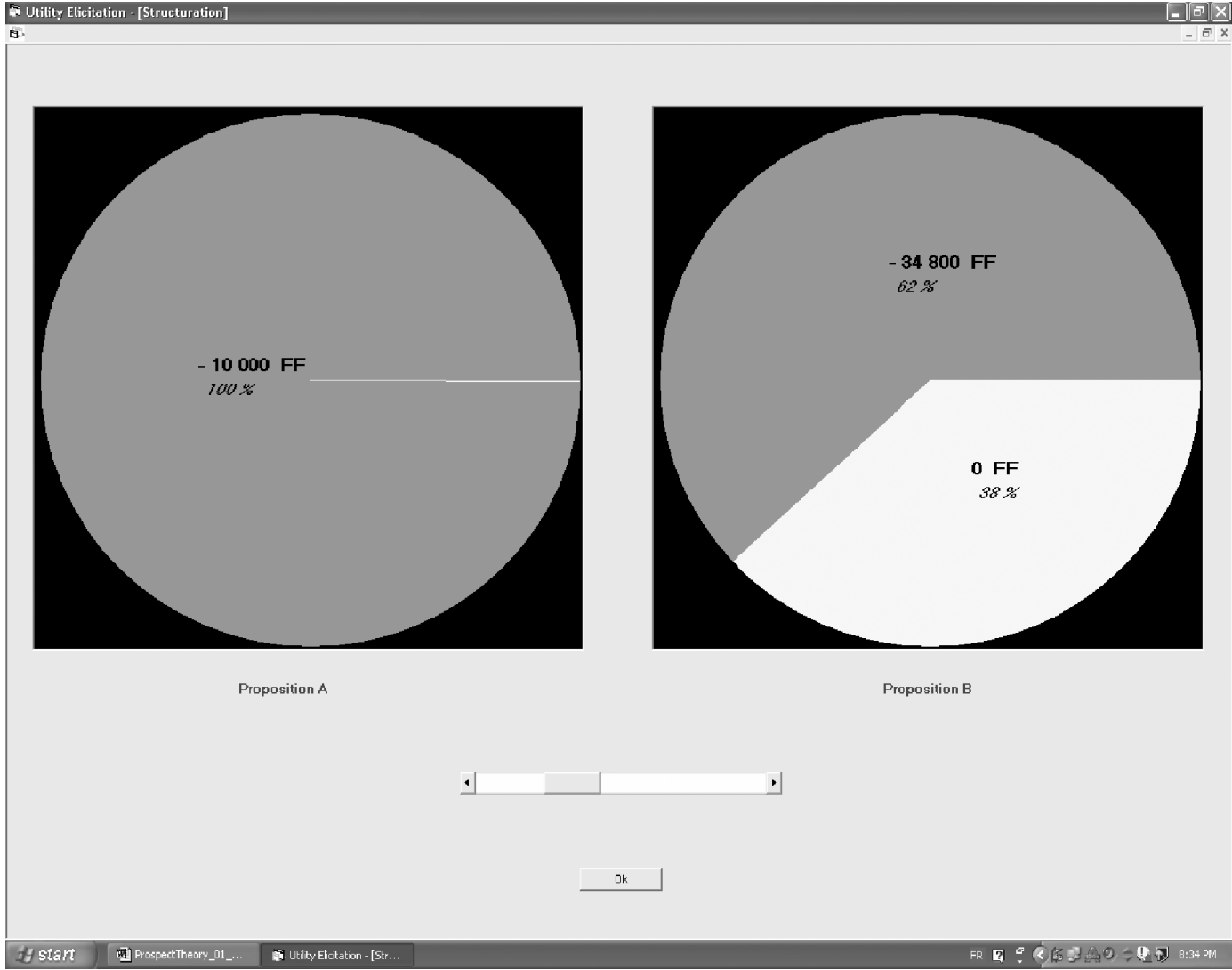


Table A1

An Illustration of the Bisection Method

\begin{tabular}{|c|c|c|}
\hline Iteration & Offered choices in elicitation of $\mathscr{L}_{1}$ & Offered choices in elicitation of $L_{0.0625}$ \\
\hline 1 & $(-\mathbf{1}, \mathbf{0 0 0}, \mathbf{0 . 3 3} ;-\mathbf{6 0 0})$ vs. $(-4,000,0.33 ;-100)$ & $-6,080$ vs. $(-7,800,0.78 ; 0)$ \\
\hline 2 & $(-\mathbf{1}, \mathbf{0 0 0}, \mathbf{0 . 3 3} ;-\mathbf{6 0 0})$ vs. $(-2,500,0.33 ;-100)$ & $-3,040$ vs. $(-100,000,0.78 ; 0)$ \\
\hline 3 & $(-1,000,0.33 ;-600)$ vs. $(-\mathbf{1}, \mathbf{7 5 0}, \mathbf{0 . 3 3} ;-\mathbf{1 0 0})$ & $-4,560$ vs. $(-100,000, \mathbf{0 . 7 8} ; \mathbf{0})$ \\
\hline 4 & $(-1,000,0.33 ;-600)$ vs. $(-2,100,0.33 ;-100)$ & $-3,800$ vs. $(-100,000,0.78 ; 0)$ \\
\hline 5 & $(-\mathbf{1}, \mathbf{0 0 0}, \mathbf{0 . 3 3} ;-\mathbf{6 0 0})$ vs. $(-2,300,0.33 ;-100)$ & $-\mathbf{4 , 1 8 0}$ vs. $(-100,000,0.78 ; 0)$ \\
\hline Indifference value & $-2,200$ & $-4,370$ \\
\hline
\end{tabular}

Appendix C. Overview of the Main Parameters per Subject

\begin{tabular}{|c|c|c|c|c|c|c|c|c|c|c|c|c|c|}
\hline \multirow[b]{3}{*}{ Subject } & & & \multicolumn{4}{|c|}{ Power function coefficients } & \multicolumn{7}{|c|}{ Coefficients loss aversion } \\
\hline & \multicolumn{2}{|c|}{ Probability } & \multicolumn{2}{|c|}{$\begin{array}{l}\text { Prospect } \\
\text { theory }\end{array}$} & \multicolumn{2}{|c|}{$\begin{array}{c}\text { Expected } \\
\text { utility }\end{array}$} & \multicolumn{2}{|c|}{$\begin{array}{l}\text { Kahneman and } \\
\text { Tversky (1979) }\end{array}$} & \multirow[b]{2}{*}{ Neilson (2002) } & \multicolumn{2}{|c|}{$\begin{array}{c}\text { Wakker and } \\
\text { Tversky (1993) }\end{array}$} & \multirow{2}{*}{$\begin{array}{c}\text { Bowman et al. } \\
\text { (1999) }\end{array}$} & \multirow{2}{*}{$\begin{array}{l}\text { Köbberling and } \\
\text { Wakker (2005) }\end{array}$} \\
\hline & $p_{g}$ & $p_{\ell}$ & Gain & Loss & Gain & Loss & Mean & Med & & Mean & Med & & \\
\hline S1 & 0.70 & 0.40 & 1.03 & 0.70 & 0.50 & 1.03 & 4.99 & 4.11 & 3.23 & 3.45 & 2.87 & 2.19 & 20.48 \\
\hline S2 & 0.65 & 0.61 & 1.20 & 1.24 & 0.73 & 0.88 & 1.08 & 1.08 & 0.62 & 1.12 & 1.21 & 0.70 & 0.94 \\
\hline S3 & 0.56 & 0.56 & 1.02 & 0.60 & 0.84 & 0.49 & 2.49 & 2.25 & 0.92 & 1.63 & 1.63 & 0.41 & 6.45 \\
\hline S4 & 0.60 & 0.58 & 0.85 & 0.80 & 0.60 & 0.60 & 2.69 & 2.75 & 1.49 & 2.34 & 2.31 & 1.32 & 3.67 \\
\hline S5 & 0.50 & 0.68 & 0.57 & 0.85 & 0.57 & 0.46 & 0.89 & 0.85 & 0.49 & 1.22 & 1.08 & 0.42 & 0.70 \\
\hline S6 & 0.42 & 0.68 & 0.56 & 1.01 & 0.72 & 0.55 & 2.16 & 2.34 & 0.60 & 3.21 & 2.17 & 1.14 & 0.37 \\
\hline S7 & 0.60 & 0.69 & 0.96 & 0.79 & 0.69 & 0.43 & 1.86 & 1.85 & 1.43 & 1.86 & 1.84 & 1.05 & 2.06 \\
\hline S8 & 0.61 & 0.61 & 2.17 & 1.09 & 1.39 & 0.78 & 6.67 & 6.80 & 2.69 & 5.20 & 3.95 & 1.17 & 6.17 \\
\hline S9 & 0.76 & 0.42 & 1.28 & 0.66 & 0.44 & 0.85 & 2.10 & 2.08 & 0.92 & 1.45 & 1.06 & 0.41 & 4.38 \\
\hline $\mathrm{S} 10$ & 0.74 & 0.56 & 1.02 & 0.70 & 0.42 & 0.58 & 1.52 & 1.28 & 0.78 & 1.03 & 0.74 & 0.37 & 2.95 \\
\hline S11 & 0.44 & 0.60 & 0.72 & 0.68 & 0.90 & 0.48 & 1.65 & 1.72 & 0.36 & 1.63 & 1.56 & 0.44 & 1.11 \\
\hline S12 & 0.64 & 0.70 & 0.74 & 0.91 & 0.46 & 0.47 & 1.19 & 1.20 & 0.90 & 1.55 & 1.51 & 0.97 & 0.64 \\
\hline $\mathrm{S} 13$ & 0.58 & 0.58 & 0.72 & 0.67 & 0.56 & 0.52 & 1.54 & 1.39 & 0.57 & 1.37 & 1.22 & 0.43 & 2.48 \\
\hline S14 & 0.80 & 0.75 & 1.93 & 3.07 & 0.54 & 1.19 & 0.30 & 0.30 & 0.22 & 0.27 & 0.23 & 0.25 & 0.34 \\
\hline S15 & 0.56 & 0.56 & 0.59 & 0.82 & 0.49 & 0.67 & 1.45 & 1.53 & 0.67 & 2.11 & 1.84 & 0.81 & 0.59 \\
\hline S16 & 0.52 & 0.66 & 0.61 & 0.82 & 0.57 & 0.47 & 2.00 & 2.01 & 0.85 & 2.45 & 2.20 & 0.67 & 4.00 \\
\hline S17 & 0.71 & 0.77 & 1.00 & 0.85 & 0.47 & 0.31 & 3.19 & 3.06 & 2.55 & 2.84 & 2.52 & 2.16 & 3.80 \\
\hline S18 & 0.40 & 0.52 & 0.68 & 0.82 & 0.93 & 0.77 & 1.54 & 1.63 & 0.78 & 1.77 & 1.94 & 0.59 & 1.14 \\
\hline S19 & 0.63 & 0.66 & 0.96 & 0.80 & 0.61 & 0.49 & 1.45 & 1.54 & 1.04 & 1.29 & 1.30 & 0.81 & 1.09 \\
\hline S20 & 0.52 & 0.54 & 0.90 & 0.71 & 0.84 & 0.64 & 7.23 & 7.01 & 6.78 & 6.22 & 4.97 & 3.20 & 11.87 \\
\hline S21 & 0.56 & 0.62 & 0.87 & 1.02 & 0.72 & 0.69 & 1.79 & 1.93 & 1.15 & 2.03 & 1.91 & 1.55 & 1.02 \\
\hline S22 & 0.54 & 0.58 & 0.69 & 0.66 & 0.61 & 0.52 & 1.13 & 1.13 & 0.40 & 1.17 & 1.13 & 0.36 & 1.00 \\
\hline S23 & 0.54 & 0.58 & 0.84 & 0.55 & 0.73 & 0.42 & 1.99 & 1.70 & 0.44 & 1.64 & 1.23 & 0.35 & 3.83 \\
\hline S24 & 0.65 & 0.62 & 0.50 & 0.54 & 0.30 & 0.36 & 1.66 & 1.57 & 0.18 & 1.32 & 1.06 & 0.13 & 6.00 \\
\hline S25 & 0.59 & 0.63 & 0.61 & 0.33 & 0.47 & 0.23 & 3.14 & 2.53 & 0.43 & 1.38 & 1.54 & 0.12 & 56.00 \\
\hline S26 & 0.34 & 0.38 & 1.11 & 0.75 & 1.98 & 1.11 & 3.50 & 2.94 & 2.37 & 2.64 & 2.53 & 1.17 & 71.00 \\
\hline S27 & 0.84 & 0.48 & 0.38 & 0.48 & 0.10 & 0.50 & 0.86 & 0.87 & 0.06 & 1.37 & 0.92 & 0.03 & 0.35 \\
\hline S28 & 0.22 & 0.39 & 0.51 & 0.51 & 1.25 & 0.69 & 4.75 & 4.35 & 2.54 & 4.13 & 2.67 & 1.19 & 27.00 \\
\hline S29 & 0.62 & 0.63 & 0.87 & 0.75 & 0.58 & 0.51 & 1.89 & 2.06 & 1.12 & 1.97 & 2.02 & 0.88 & 1.20 \\
\hline S30 & 0.62 & 0.40 & 1.24 & 0.66 & 0.69 & 0.85 & 0.58 & 0.63 & 0.36 & 0.59 & 0.39 & 0.22 & 0.20 \\
\hline S31 & 0.58 & 0.56 & 2.05 & 0.71 & 1.45 & 0.59 & 2.30 & 1.92 & 1.01 & 1.21 & 0.90 & 0.23 & 14.00 \\
\hline S32 & 0.44 & 0.64 & 0.49 & 1.01 & 0.58 & 0.64 & 0.52 & 0.41 & 0.30 & 1.10 & 0.88 & 0.36 & 0.28 \\
\hline S33 & 0.58 & 0.68 & 0.72 & 1.08 & 0.55 & 0.50 & 1.48 & 1.46 & 0.71 & 1.35 & 1.12 & 1.22 & 1.90 \\
\hline S34 & 0.64 & 0.60 & 0.46 & 0.80 & 0.30 & 0.56 & 1.04 & 1.06 & 0.22 & 1.18 & 1.07 & 0.26 & 0.70 \\
\hline S35 & 0.47 & 0.61 & 0.71 & 0.60 & 0.78 & 0.43 & 4.12 & 3.77 & 2.51 & 4.31 & 3.49 & 1.42 & 17.77 \\
\hline S36 & 0.40 & 0.30 & 0.56 & 0.58 & 0.78 & 1.16 & 2.05 & 2.05 & 0.42 & 2.18 & 2.15 & 0.34 & 2.67 \\
\hline S37 & 0.67 & 0.71 & 0.86 & 0.81 & 0.48 & 0.38 & 4.68 & 4.32 & 3.15 & 4.61 & 4.12 & 2.68 & 5.40 \\
\hline S38 & 0.61 & 0.44 & 1.32 & 0.74 & 0.87 & 0.88 & 1.62 & 1.57 & 1.22 & 1.27 & 1.06 & 0.42 & 1.22 \\
\hline S39 & 0.72 & 0.66 & 0.66 & 0.60 & 0.29 & 0.36 & 1.73 & 1.76 & 0.37 & 1.54 & 1.49 & 0.31 & 2.77 \\
\hline S40 & 0.40 & 0.38 & 0.71 & 0.59 & 0.95 & 0.82 & 1.72 & 1.68 & 0.91 & 1.52 & 1.36 & 0.41 & 2.55 \\
\hline S41 & 0.68 & 0.22 & 0.50 & 0.51 & 0.29 & 1.09 & 0.86 & 0.87 & 0.27 & 1.04 & 1.19 & 0.09 & 1.21 \\
\hline S42 & 0.68 & 0.67 & 0.69 & 0.66 & 0.39 & 0.37 & 1.21 & 1.14 & 0.33 & 1.10 & 1.05 & 0.28 & 2.53 \\
\hline S43 & 0.60 & 0.58 & 0.67 & 0.81 & 0.48 & 0.62 & 1.66 & 1.66 & 0.77 & 1.64 & 1.46 & 0.59 & 2.79 \\
\hline S44 & 0.60 & 0.63 & 0.60 & 0.62 & 0.43 & 0.40 & 2.51 & 2.41 & 0.67 & 2.41 & 2.48 & 0.49 & 23.33 \\
\hline S45 & 0.74 & 0.44 & 0.51 & 1.57 & 0.23 & 2.01 & 0.58 & 0.40 & 0.25 & 1.28 & 0.79 & 0.36 & 0.22 \\
\hline S46 & 0.77 & 0.14 & 0.63 & 0.50 & 0.25 & 2.04 & 3.22 & 2.37 & 0.77 & 4.23 & 2.10 & 0.33 & 55.00 \\
\hline S47 & 0.52 & 0.50 & 0.66 & 0.87 & 0.61 & 0.87 & 0.80 & 0.80 & 0.23 & 0.93 & 0.93 & 0.30 & 0.68 \\
\hline S48 & 0.58 & 0.62 & 1.35 & 0.43 & 1.03 & 0.30 & 2.30 & 1.64 & 0.40 & 1.20 & 0.79 & 0.11 & 19.00 \\
\hline
\end{tabular}




\section{References}

Abdellaoui, M. 2000. Parameter-free elicitation of utilities and probability weighting functions. Management Sci. 46 1497-1512.

Abdellaoui, M., C. Barrios, P. P. Wakker. 2007. Reconciling introspective utility with revealed preference: Experimental arguments based on prospect theory. J. Econometrics 138 356-378.

Abdellaoui, M., F. Vossmann, M. Weber. 2005. Choice-based elicitation and decomposition of decision weights for gains and losses under uncertainty. Management Sci. 51 1384-1399.

Barberis, N., M. Huang, T. Santos. 2001. Prospect theory and asset prices. Quart. J. Econom. 66 1-53.

Benartzi, S., R. H. Thaler. 1995. Myopic loss aversion and the equity premium puzzle. Quart. J. Econom. 110 73-92.

Blavatskyy, P. 2006. Error propagation in the elicitation of utility and probability weighting functions. Theory Decision $\mathbf{6 0}$ 315-334.

Bleichrodt, H., J. L. Pinto. 2000. A parameter-free elicitation of the probability weighting function in medical decision analysis. Management Sci. 46 1485-1496.

Bleichrodt, H., J. L. Pinto. 2002. Loss aversion and scale compatibility in two-attribute trade-offs. J. Math. Psych. 46 315-337.

Bleichrodt, H., J. L. Pinto, P. P. Wakker. 2001. Using descriptive findings of prospect theory to improve the prescriptive use of expected utility. Management Sci. 47 1498-1514.

Booij, A. S., G. van de Kuilen. 2006. A parameter-free analysis of the utility of money for the general population under prospect theory. Working paper, University of Amsterdam, Amsterdam, The Netherlands.

Bowman, D., D. Minehart, M. Rabin. 1999. Loss aversion in a consumption-savings model. J. Econom. Behav. Organ. 38 155-178.

Camerer, C. F. 1995. Individual decision making. J. Kagel, A. Roth, eds. The Handbook of Experimental Economics. Princeton University Press, Princeton, NJ, 587-703.

Camerer, C. F. 2000. Prospect theory in the wild: Evidence from the field. D. Kahneman, A. Tversky, eds. Choices, Values, and Frames. Cambridge University Press, New York, 288-300.

Camerer, C. F., T.-H. Ho. 1994. Nonlinear weighting of probabilities and violations of the betweenness axiom. J. Risk Uncertainty 8 167-196.

Camerer, C. F., R. M. Hogarth. 1999. The effects of financial incentives in experiments: A review and capital-labor-production framework. J. Risk Uncertainty 19 7-42.

Camerer, C. F., L. Babcock, G. F. Loewenstein, R. H. Thaler. 1997. Labor supply of New York city cabdrivers: One day at a time. Quart. J. Econom. 112 407-442.

Currim, I. S., R. K. Sarin. 1989. Prospect versus utility. Management Sci. 35 22-41.

Dunn, L. F. 1996. Loss aversion and adaptation in the labour market: Empirical indifference functions and labour supply. Rev. Econom. Statist. 78 441-450.

Etchart-Vincent, N. 2004. Is probability weighting sensitive to the magnitude of consequences? An experimental investigation on losses. J. Risk Uncertainty 28 217-235.

Fennema, H., M. van Assen. 1998. Measuring the utility of losses by means of the trade-off method. J. Risk Uncertainty 17 277-295.

Fishburn, P. C., G. A. Kochenberger. 1979. Two-piece von Neumann Morgenstern utility functions. Decision Sci. 10 503-518.

Goette, L., D. Huffman, E. Fehr. 2004. Loss aversion and labour supply. J. Eur. Econom. Assoc. 2 216-228.

Gonzalez, R., G. Wu. 1999. On the form of the probability weighting function. Cognitive Psych. 38 129-166.

Hardie, B. G. S., E. J. Johnson, P. S. Fader. 1993. Modeling loss aversion and reference dependence effects on brand choice. Marketing Sci. 12 378-394.
Heath, C., S. Huddart, M. Lang. 1999. Psychological factors and stock option exercise. Quart. J. Econom. 114 601-627.

Hershey, J. C., P. J. H. Schoemaker. 1985. Probability versus certainty equivalence methods in utility measurement: Are they equivalent? Management Sci. 31 1213-1231.

Hertwig, R., A. Ortmann. 2001. Experimental practices in economics: A methodological challenge for psychologists? Behavioral Brain Sci. 24 383-451.

Kahneman, D., A. Tversky. 1979. Prospect theory: An analysis of decision under risk. Econometrica 47 263-291.

Kahneman, D., J. L. Knetsch, R. H. Thaler. 1990. Experimental test of the endowment effect and the Coase theorem. J. Political Econom. 98 1325-1348.

Köbberling, V., P. P. Wakker. 2003. Preference foundations for nonexpected utility: A generalized and simplified technique. Math. Oper. Res. 28 395-423.

Köbberling, V., P. P. Wakker. 2005. An index of loss aversion. J. Econom. Theory 122 119-131.

Laughhunn, D. J., J. W. Payne, R. Crum. 1980. Managerial risk preferences for below-target returns. Management Sci. 26 1238-1249.

Luce, R. D. 2000. Utility of Gains and Losses: Measurement-Theoretical and Experimental Approaches. Lawrence Erlbaum Associates, Mahwah, NJ.

Mehra, R., E. C. Prescott. 1985. The equity premium: A puzzle. J. Monetary Econom. 15 145-161.

Myagkov, M., C. R. Plott. 1997. Exchange economies and loss exposure: Experiments exploring prospect theory and competitive equilibria in market environments. Amer. Econom. Rev. 87 801-828.

Neilson, W. S. 2002. Comparative risk sensitivity with referencedependent preferences. J. Risk Uncertainty 24 131-142.

Novemsky, N., D. Kahneman. 2005. The boundaries of loss aversion. J. Marketing Res. 42 119-128.

Pennings, J. M. E., A. Smidts. 2003. The shape of utility functions and organizational behavior. Management Sci. 49 1251-1263.

Rabin, M. 2000. Risk aversion and expected-utility theory: A calibration theorem. Econometrica 68 1281-1292.

Ramsey, F. P. 1931. The Foundations of Mathematics and Other Logical Essays. Routledge and Kegan Paul, London, UK.

Saha, A. 1993. Expo-power utility: A "flexible" form for absolute and relative risk aversion. Amer. J. Agricultural Econom. 75 905-913.

Schmidt, U., S. Traub. 2002. An experimental test of loss aversion. J. Risk Uncertainty 25 233-249.

Schmidt, U., H. Zank. 2005. What is loss aversion? J. Risk Uncertainty 30 157-167.

Schunk, D., C. Betsch. 2006. Explaining heterogeneity in utility functions by individual differences in decision modes. J. Econom. Psych. 27 386-401.

Starmer, C. 2000. Developments in non-expected utility theory: The hunt for a descriptive theory of choice under risk. J. Econom. Literature 28 332-382.

Tversky, A., C. Fox. 1995. Weighing risk and uncertainty. Psych. Rev. 102 269-283.

Tversky, A., D. Kahneman. 1991. Loss aversion in riskless choice: A reference-dependent model. Quart. J. Econom. 56 1039-1061.

Tversky, A., D. Kahneman. 1992. Advances in prospect theory: Cumulative representation of uncertainty. J. Risk Uncertainty 5 297-323.

Vind, K. 2003. Independence, Additivity, Uncertainty. Springer Verlag, Berlin, Germany.

Wakker, P. P., D. Deneffe. 1996. Eliciting von NeumannMorgenstern utilities when probabilities are distorted or unknown. Management Sci. 42 1131-1150.

Wakker, P. P., A. Tversky. 1993. An axiomatization of cumulative prospect theory. J. Risk Uncertainty 7 147-176.

Wu, G., R. Gonzalez. 1996. Curvature of the probability weighting function. Management Sci. 42 1676-1690. 